\title{
Surface-capped copper nanoadditive for improvement of base oil properties
}

\author{
F. Shaon, A. A. Rana, S. M. Masum, M. A. Ullah and M. M. Karim* \\ Department of Applied Chemistry and Chemical Engineering, University of Dhaka, Dhaka-1000, Bangladesh
}

Received: 19 June 2018

Revised: 11 July 2018

Accepted: 03 December 2018

DOI: https://doi.org/10.3329/bjsir.v54i1.40725

\begin{abstract}
Copper nanoparticles surface-capped by alkanethiol with long carbon chain length was prepared successfully by chemical reduction method. 1-dodecanethiol was used as the coating material for the desired smooth and protected surface. Various reaction parameters, like effect of $\mathrm{pH}$, molar ratio of the reactants etc. had been tested experimentally to explore the most suitable and economical way of using the chemical reduction method. Uniform, smooth surface and spherical shaped copper nanoparticles, with particle size of about $40-60 \mathrm{~nm}$ had been produced successfully. Copper nanoparticles surface-capped by alkanethiol $\left(\mathrm{C}_{12} \mathrm{~S}-\mathrm{Cu}\right)$ was characterized by means of x-ray diffraction, scanning electron microscopy, Fourier transform infrared spectrometry and ultraviolet-visible spectroscopy. Uniform dispersion of copper nanoadditive in base oil using ultrasonic method was investigated. The tribological behavior of $\mathrm{C}_{12} \mathrm{~S}-\mathrm{Cu}$ as an additive for base oil was evaluated. Viscosity, pour point, and flash point of nano lubricants at different concentrations of nanoadditive $(0.2$, and $0.5 \mathrm{wt} \%)$ were evaluated.
\end{abstract}

Keywords: Copper nanoparticles; 1-dodecanethiol; X-ray diffraction; Scanning electron microscopy; Fourier transform infrared spectrometry

\section{Introduction}

A number of studies have been conducted in relation to the synthesis and characterization of various inorganic nanoparticles as well as the effect of nano-sized lubricant additives on wear and friction with the development of nano technology (Zhou et al., 2001; Sun et al., 2004; Liu and Chen, 2000). It has been generally recognized that the mechanisms for nanoparticle lubricating additives to reduce friction and wear are mainly linked with three aspects (Zhang et al., 2011). First, spherical nanoparticles behave as ball-bearings between rubbing surfaces to reduce friction and wear by way of polishing surface and increasing surface hardness (Xu et al., 1996). Second, nanoparticles in lubricating oil can fill wear scars and grooves and form physico-chemical adsorption film resulting in reduced friction and wear (Choi et al., 2009). Finally, colloid nanoparticle additives, in particular, soft metal nanoparticles and their alloys can penetrate the elastohydrodynamic contacts mainly by a mechanism of mechanical entrapment in thin film contacts, or they can form boundary lubricating films in rolling contacts at slow speeds, both resulting in improved load carrying capacity, antiwear and friction reduction properties (Chinas-Castillo and Spikes, 2003, 2004; Zhang et al., 2010).

In addition to the distinctive catalytic, optical, thermal, magnetic, antimicrobial, electronic and electrical conducting properties, copper nanoparticles (Cu-NPs) present a wide range of potential applications in nanotechnology including catalysts (Judai et al., 2011), additives for lubricants (Shi et al., 2013), heat transfer nanofluids (Garg et al., 2008), manufacture of electronic and optical devices (Pacioni et al., 2010), conductive inks (Park et al., 2007), materials for solar energy conversion (Musa et al., 1998), biosensors (Kumar et al., 2010), antibiofouling agents (Kumari and Majewski, 2013) and cancer cell treatments (Mamun et al., 2009). Moreover, due to the remarkable tribological properties of $\mathrm{Cu}$ nanoparticles, together with good self-repair functions to the worn surface, and an excellent environmental-friendly property, they have been desired for an excellent candidate to replace expensive noble metal nanoparticles such as silverand gold (Khanna et al., 2007; Luo et al., 2012; Seo et al., 2013). 
There are diverse approaches to the preparation of the nanoscale materials that have been reported in the literature. Some of these methods include chemical reduction (Huang et al., 1997; Lisiecki et al., 1996), radiation method (Joshi et al., 1998), microemulsion technique (Lisiecki and Pileni 1993, Pileni et al., 1999; Qi et al., 1997), supercritical technique (Ziegler et al., 2001), thermal reduction (Dhas et al., 1998), sonochemical reduction (Kumar et al., 2001), and laser ablation (Yeh et al., 1999). We can focus on the chemical reduction method over other nanoparticle preparation techniques because of its ease of application, cost-effectiveness, variation in particle characteristics and different experimental parameters such as concentration, temperature and $\mathrm{pH}$ (Grouchko et al., 2009).

Nanoparticles are likely to agglomerate in liquid medium because of large specific surface and high surface energy, which greatly restrict the application of nanoparticles as lubricating additives (Cushing et al., 2004). To overcome this obstruction, researchers usually adopt polyelectrolytes (Radtchenko et al., 2001; Li et al., 2006) and surfactants (Shen et al., 2009; Puntes et al., 2001; Zhang et al., 2003) as modifiers to control the growth of particles and to coat nanoparticles, thereby preventing them from surface oxidation or aggregation (Hou et al., 2005, Sun and Xia, 2002).

In the case of copper NPs some surfactants were usually added as dispersant or surface modifier such as sodium dodecyl sulfate (SDS) (Lisiecki et al., 1996), poly(vinylpyrrolidone) (PVP) (Park et al., 2007a), dialkyldithiophospate (Zhang et al., 2009), alkyl aryl-sulfonate (AAS) (Lee et al., 2009), cetyltrimethylammonium bromide (CTAB) (Chen et al., 2006), and polyelectrolytes such as poly (ethyleneimine), polyethylene glycols, and poly (ethylether ketone) (Dung et al., 2011). Among them CTAB plays a critical role in controlling the size and improve the disperse ability of copper nanoparticles (Chen et al., 2006).

The aim of capping ligands in synthesis of copper nanoparticles is to bind with the particle surfaces. They provide a steric barrier to aggregation and are also effective in preventing inorganic nanoparticles from oxidation, setting up ground for them to be used as lubricating additives. But most of the currently used surfaces modifying agents have phosphorus and sulphur which are harmful to environment and human body (Zhou et al., 2001; Zhang et al., 2010). Therefore it is important to seek for novel P- and S-free surface modifying agents for $\mathrm{Cu}$ nanoparticle so as to make an environmentally acceptable nano- $\mathrm{Cu}$ lubricant additive (Zhu et al., 2009). In particular, alkanethiol-capped nanoparticles (monolayer protected clusters, MPCs) are stable in air, soluble in nonpolar organic solvents, and capable of facile modification with other thiols through exchange reactions. In addition longer chains of octanethiol, decanethiol and dodecanethiol $\left(\mathrm{C}_{8}-\mathrm{C}_{12}\right.$ alkanethiols $)$ were suggested for a good barrier layer that can protect the copper cores from oxidation (Ang et al., 2004).MPCs are generally stabilized with thiolated ligands that are known to covalently bond to metal surfaces, with their properties primarily determined by the terminal functional groups. Among thiol-capped metal nanoparticles, $\mathrm{Au}$ and Ag probably have been studied extensively due to their simplicity of preparation and relative stability (Lisiecki et al., 2000; Henglein, 1998).

We addressed on a successful preparation of copper-nanoadditive surface capped by 1-dodecanethiol by chemical reduction method. A complete characterization of the nanoadditive was performed by various techniques such as Fourier transform infrared (FT-IR) spectroscopy, X-ray powder diffraction (XRD), ultraviolet-visible (UV-vis) spectroscopy, scanning electron microscope (SEM), energy dispersive X-ray spectroscopy (EDX).Particle size distribution of the nanoparticles was between $60-80 \mathrm{~nm}$. Uniform dispersion of copper nanoadditive in base oil using ultrasonic method was investigated. The tribological behavior of $\mathrm{C}_{12} \mathrm{~S}-\mathrm{Cu}$ as an additive in base oil was investigated. Viscosity, pour point and flash point of nano lubricants at different concentrations $(0.2$, and $0.5 \mathrm{wt} \%)$ were evaluated.

\section{Materials and methods}

\section{Materials}

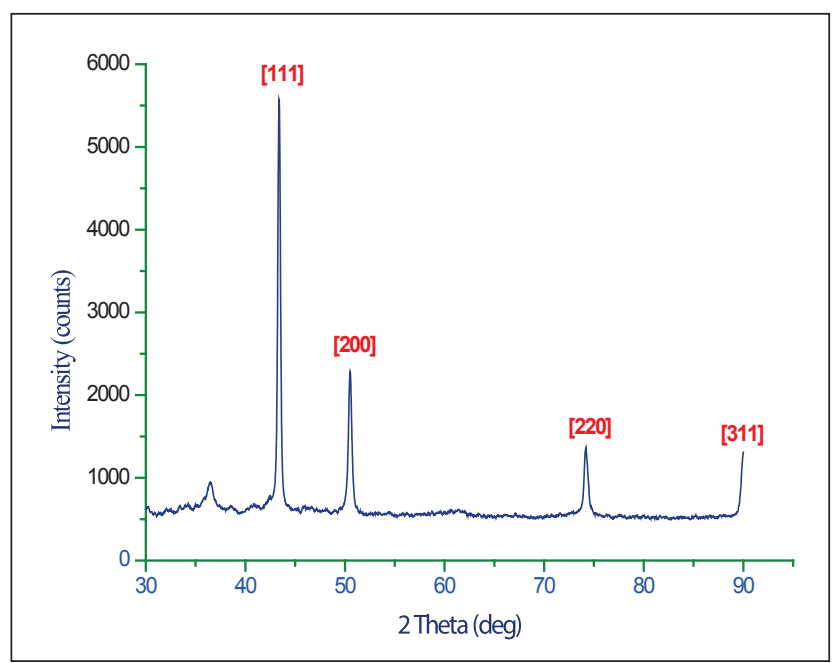

Fig. 1. X-ray powder diffraction patterns of synthesized copper nanoparticles 
Copper sulfate pentahydrate $\left(\mathrm{CuSO}_{4} .5 \mathrm{H}_{2} \mathrm{O}, \mathrm{AR}\right.$ grade) and toluene $\left(\mathrm{C}_{6} \mathrm{H}_{6}\right)$ were obtained from Merck Specialties Private Ltd. Mumbai, India. 1-dodecanethiol $\left(\mathrm{CH}_{3}\left(\mathrm{CH}_{2}\right)_{11} \mathrm{SH}\right)$, cetyltrimethylammonium bromide (CTAB, 99\% grade) and hydrazine hydrate $\left(\mathrm{N}_{2} \mathrm{H}_{5} \mathrm{OH}\right)$ used were the products of Loba Chemie Pvt. Ltd. Mumbai, India. Ethanol $\left(\mathrm{C}_{2} \mathrm{H}_{5} \mathrm{OH}\right)$ was obtained from Merck KGaA, Germany. Dichloromethane $\left(\mathrm{CH}_{2} \mathrm{Cl}_{2}\right)$ was purchased from Riedel-de Haen, Germany and base oil SN-150 was collected from Renish Petrochem FZE (Trading company of virgin base oil based in Dubai), United Arab Emirates. Water is purified by distillation process and maintains the water quality of $0.1 \mu \mathrm{S} / \mathrm{cm}$ throughout the work.

\section{Instruments}

Absorption spectra of reaction solutions were measured by UV-vis spectrophotometer (UV-1800), CPS-240A model, Shimadzu Corporation, JAPAN. The XRD pattern of the synthesized copper nanoparticles was recorded by a Diffractometer, Ultima-IV model, Shimadzu Corporation, JAPAN, operating at $40 \mathrm{KV}$ and $40 \mathrm{~mA}$ over a diffraction angle from $30^{\circ}$ to $90^{\circ}$ under a scan rate of $0.02^{\circ}$ per step at a speed of $3.0 \mathrm{deg} / \mathrm{min}$. The Scanning Electron Microscopy (SEM) analysis coupled with EDX analysis of synthesized copper nanoparticles was performed by JEOL Field Emission Scanning Electron Microscope, JSM-7600F model, JAPAN, operating at $5.0 \mathrm{KV}$, with a width of $8.5 \mathrm{~mm}$ and magnification was X 15,000; 30,000; 50,000 and 1,00,000. The Attenuated Total Reflectance (ATR) and FT-IR spectroscopy of synthesized copper nanoparticles and the capping agent 1-dodecanethiol were carried out by FT-IR Spectrophotometer, IRPrestige-21 model, Shimadzu Corporation, JAPAN, equipped with an ATR device in the wavenumber range $500-4000 \mathrm{~cm}^{-1}$ with 20 scanning rate with resolution of $4 \mathrm{~cm}^{-1}$. The FT-IR spectra were taken in a transmittance mode.

\section{Preparation of surface-capped $\mathrm{Cu}$-nanoparticles}

The details about the preparation of surface-modified $\mathrm{Cu}$ nanoparticles are as follows: $2.497 \mathrm{~g}$ (10 mmol) copper sulfate was dissolved completely in $50 \mathrm{~mL}$ of distilled water. $0.456 \mathrm{~g}$ (1.25 mmol) CTAB was first dispersed into the distilled water using the sonicator and then into the copper sulfate solution, CTAB was added under vigorous stirring. Then approximately $12 \mathrm{~mL}$ of hydrazine hydrate was added drop-wise into the mixed solution to rapidly change the solution color into dark brown. The mixture was stirred for 10 $\min$ at $30^{\circ} \mathrm{C}$, followed by the addition of $2.4 \mathrm{~mL} 1$-dodecanethiol in $50 \mathrm{~mL}$ toluene under additional $3 \mathrm{~h}$ vigorous stirring at $30^{\circ} \mathrm{C}$.After stirring for a long time, it was assumed that all reactions were completed and then the organic layer was collected using separating funnel. Then toluene was removed with a rotary evaporator under reduced pressure, yielding crude nanosized copper surface-capped with alkanethiol. The crude product was fully washed with ethanol for several times to remove residual ligands and other impurities, affording purified surface-capped copper nanoparticles as a black powder. As-obtained black powder $\mathrm{C}_{12} \mathrm{~S}-\mathrm{Cu}$ was centrifuged and washed with ethanol and dried in the vacuum dryer at $120^{\circ} \mathrm{C}$ before characterization and tribological investigation.

\section{Preparation of nano lubricants}

Ultrasonic method was used to disperse nanoparticles inside the base oil bath. To achieve the best and the most stable state, $0.2 \mathrm{wt} \%$ and $0.5 \mathrm{wt} \%$ sample of oil $/ \mathrm{Cu}$ - have been made by dispersing at $40^{\circ} \mathrm{C}$ for $30 \mathrm{~min}$ and at $100^{\circ} \mathrm{C}$ for $60 \mathrm{~min}$ respectively. All of the samples were kept in the transparent glass containers in a completely stagnant condition for about $72 \mathrm{~h}$ for evaluating their stability conditions. During this period, the stable conditions of all the samples were periodically and visually inspected. The same procedure was followed to synthesize uncapped copper nanoparticles except that no capping agent was used.

\section{Results and discussion}

\section{$X$-ray diffraction}

Typical XRD patterns of synthesized copper nanoparticles are shown in the Fig. 1.

As shown in Fig. 1. four main characteristic diffraction peaks at $2 \theta=43.36,50.48,74.14$ and $90^{\circ}$ correspond to the [111], [200], [220] and [311] crystal planes of metallic $\mathrm{Cu}$, confirming the formation of pure face-centered-cubic (fcc) $\mathrm{Cu}$ nanoparticles without significant oxides or other impurity phases such as $\mathrm{CuO}, \mathrm{Cu}_{2} \mathrm{O}$, or $\mathrm{Cu}(\mathrm{OH})_{2}$. These are in close agreement to the JCPDS File No. 04-0836. This indicated that the prepared $\mathrm{Cu}$ material was highly pure, crystalline and well arranged in specific orientation. The sample stored for 30 days in ambient condition shows the same XRD peaks, corresponding to good stability of synthesized $\mathrm{Cu}$ nanoparticles. From the Debye-Scherrer equation (Langford and Wilson 1978, Monshi et al., 2012), we estimated the particlesize. The crystal size of products as calculated by Scherrerformula is $48.6 \mathrm{~nm}$.

\section{Surface morphology}

$\mathrm{Cu}$ nano particles are spherical in shape with a smooth surface morphology. The diameter of the nano particles is found to be ranging from $40 \mathrm{~nm}$ to $60 \mathrm{~nm}$. SEM image also 


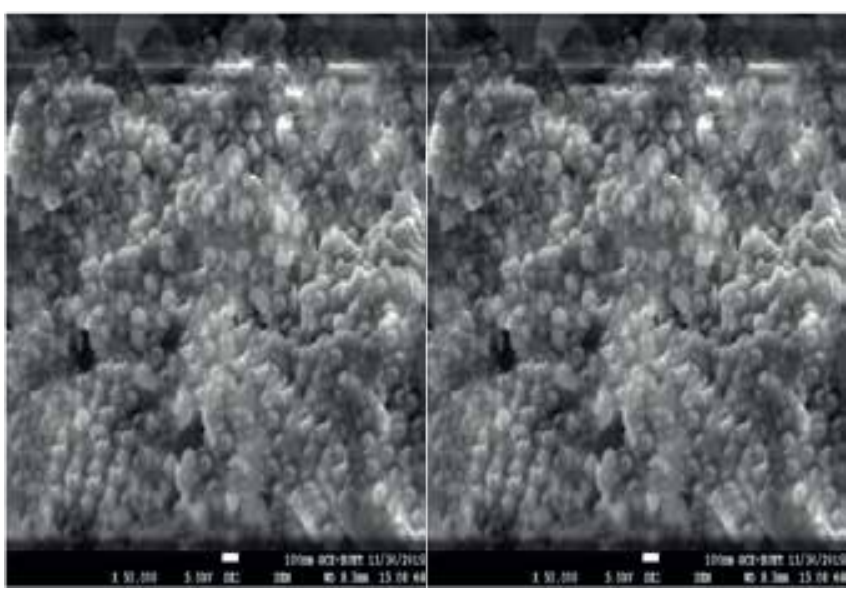

Fig. 2. SEM images of synthesized copper nanoparticles

shows that the produced nanoparticles are more or less uniform in size and shape. The agglomeration of the particles is almost clear (Fig.2). As the nanocopper particle is encapsulated by 1-dodecanethiol, there is no surface oxidation and hence prevents the oxidation of the nanocopper particle. During chemical reduction, the reducing agent donates electrons to the copper ions $\left(\mathrm{Cu}^{2+}\right)$, causing copper to convert to its metallic form $\left(\mathrm{Cu}^{0}\right)$. In case of using CTAB as protecting agent, the stabilization of $\mathrm{Cu}^{2+}$ was highly effective. $\mathrm{Cu}$ Nanoparticles (NPs) have a high surface area to volume ratio along with high fraction of surface atoms that elicits elevated lubrication activity compared to the copper metal as a whole. $\mathrm{C}_{12} \mathrm{~S}-\mathrm{Cu}$ nanoparticles were prepared under different reaction conditions and SEM images obtained are shown in the Fig 3.
It can be shown that when the $\mathrm{pH}$ value of copper sulfate solution was adjusted to alkaline $(\mathrm{pH}=10)$, without CTAB introduced into the reactant solution, large aggregates with severe agglomeration were obtained (Fig. 3 a). When the $\mathrm{pH}$ value of copper sulfate solution was not adjusted, and no CTAB stabilizer was introduced into the reactant solution, aggregates with moderate agglomeration were produced (Fig. $3 \mathrm{~b}$ ).However, when $1.25 \mathrm{mmol}$ CTAB was added into the solution, fine spherical $\mathrm{Cu}$ nanoparticles with a size of about 60-80 nm were harvested even when the $\mathrm{pH}$ value of the reactant solution was not adjusted to alkaline condition (Fig. $3 \mathrm{c})$. This is closely related to the strong reduction ability of hydrazine hydrate in alkaline conditions and to the stabilizing actions of CTAB. Namely, $\mathrm{Cu}^{2+}$ is instantly reduced into uncapped $\mathrm{Cu}$ nanoparticles by hydrazine hydrate in alkaline solution and uncapped $\mathrm{Cu}$ nanoparticles tend to agglomerate in the absence of stabilizer CTAB generating aggregates before being surface-capped by $\mathrm{C}_{12} \mathrm{SH}$. Lowering the $\mathrm{pH}$ value of copper sulfate solution slows the reduction of $\mathrm{Cu}^{2+}$ by hydrazine hydrate affording better dispersed uncapped $\mathrm{Cu}$ nanoparticles but not aggregates. After CTAB is added into the $\mathrm{CuSO}_{4}$ solution, CTAB may surround nascent $\mathrm{Cu}$ particles to prevent them from agglomeration and keep them off $\mathrm{O}_{2}$ in the aqueous solution yielding fine $\mathrm{C}_{12} \mathrm{~S}-\mathrm{Cu}$ nanoparticles with a narrow size distribution. The role of $\mathrm{CTAB}$ is to control the growth of the $\mathrm{Cu}$ nucleus to some extent and facilitate final surface-capping of $\mathrm{Cu}$ nanoparticles by $\mathrm{C}_{12} \mathrm{SH}$ possessing good oxidation resistance and dispersibility. This can be rationally understood because $\mathrm{CTAB}$ as a ligand is weaker than thiol, $\mathrm{Cu}$ nanocrystals coated by $\mathrm{CTAB}$ can be easily replaced by thiol via ligand exchange. Since stabilizer CTAB plays an important role in
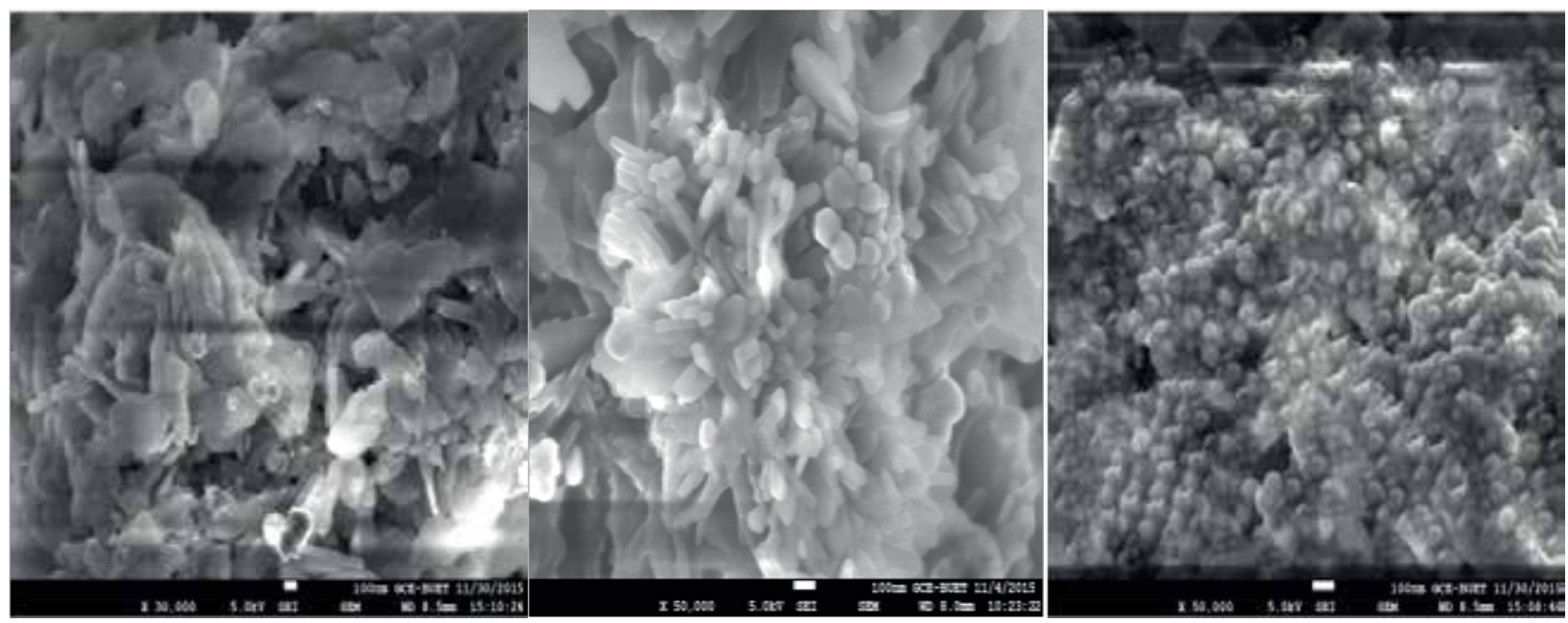

Fig. 3. SEM images of $\mathrm{C}_{12} \mathrm{~S}-\mathrm{Cu}$ nanoparticles prepared when (a) the $\mathrm{pH}$ of $\mathrm{CuSO}_{4}$ solution was adjusted to 10 in the absence of CTAB, (b) the $\mathrm{pH}$ of $\mathrm{CuSO}_{4}$ solution was not adjusted and no CTAB was added, and (c) $1.25 \mathrm{mmol}$ CTAB was added but the $\mathrm{pH}$ of aqueous $\mathrm{CuSO}_{4}$ was not adjusted 
preparing well-dispersed $\mathrm{Cu}$ nanoparticles, and we investigated the influence of molar ratio of CTAB to $\mathrm{CuSO}_{4}$ on the size and morphology of as-synthesized $\mathrm{C}_{12} \mathrm{~S}-\mathrm{Cu}$ nanoparticles. detected. The result indicates that the as- synthesized product is composed of high purity $\mathrm{Cu}$ nanoparticles. The similar EDX spectrum was obtained for each sample analyzed.

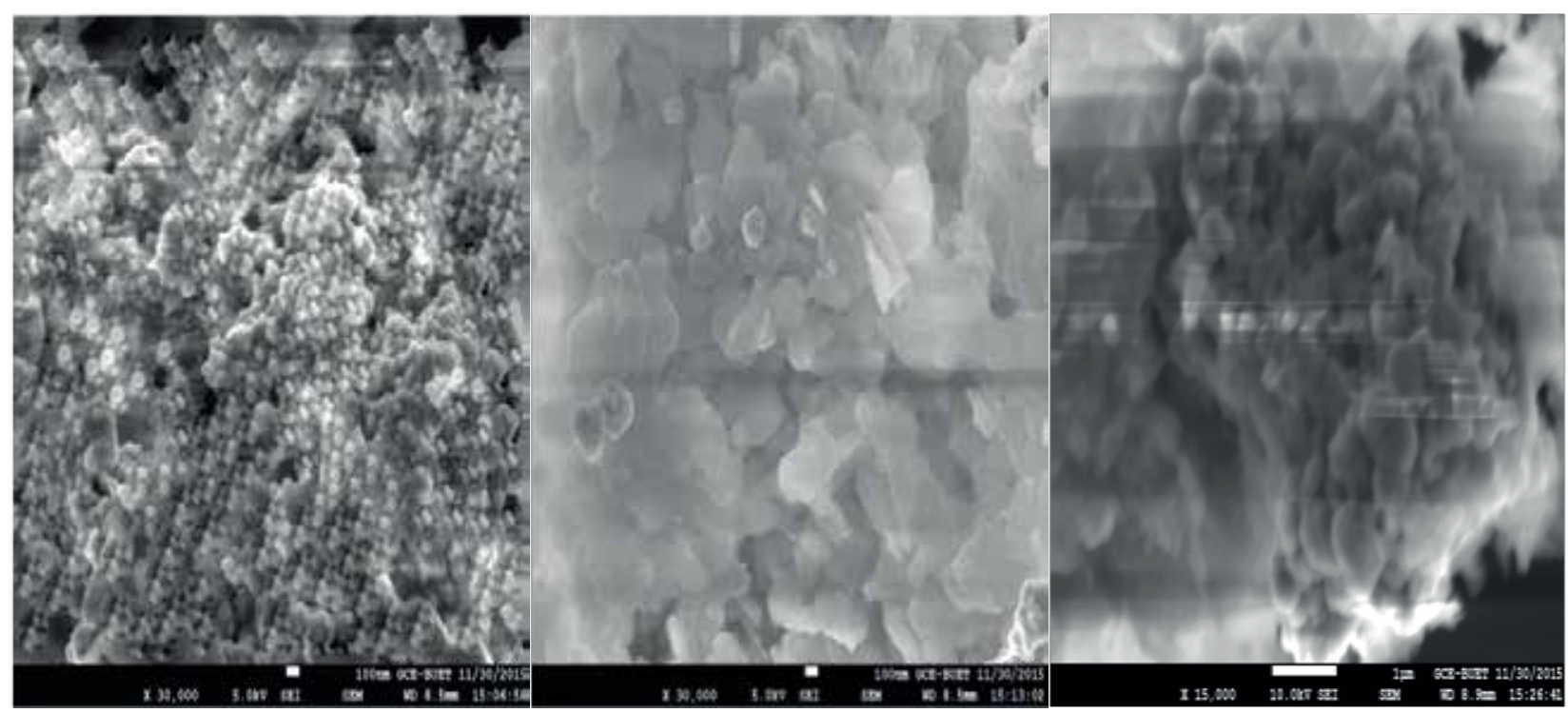

Fig. 4. SEM images of $\mathrm{C}_{12} \mathrm{~S}-\mathrm{Cu}$ nanoparticles prepared at different cetyltrimethyl ammonium bromide to $\mathrm{CuSO}_{4}$ molar ratio: (a) $1: 4$, (b) $1: 8$, (c) $1: 12$

Fig. 4 shows the SEM images of samples obtained at various molar ratio of CTAB to $\mathrm{CuSO}_{4} \cdot \mathrm{Cu}$ nanoparticles obtained at a CTAB to $\mathrm{CuSO}_{4}$ molar ratio of 1:4 have a spherical shape and a particle diameter of about 60-80 nm (Fig 4a). At increased molar ratios of CTAB to $\mathrm{CuSO}_{4}$ an oily organic layer which can be hardly separated and removed is formed around as-synthesized $\mathrm{Cu}$ nanoparticles (Fig $4 \mathrm{c}$ ). Because decreasing molar ratio of $\mathrm{CTAB}$ to $\mathrm{CuSO}_{4}$ (at $\mathrm{CTAB}$ to $\mathrm{CuSO}_{4}$ molar ratio of $1: 8$ and $1: 12$ ) leads to an increased particle size and agglomeration of $\mathrm{Cu}$ nanoparticles (Figs $4 \mathrm{~b}$ and $4 \mathrm{c}$ ) proper $\mathrm{CTAB}$ to $\mathrm{CuSO}_{4}$ molar ratio at 1:4 for synthesizing desired $\mathrm{C}_{12} \mathrm{~S}-\mathrm{Cu}$ nanoparticles can be suggested.

\section{Energy dispersive $X$-ray analysis (EDX)}

The elemental analysis of the copper nanoparticles was performed using the EDX on the SEM. Fig. 5. Shows the EDX spectrum of the spherical nanoparticles prepared with hydrazine hydrate as a reducing agent. The peaks around $0.930 \mathrm{keV}, 2.307 \mathrm{keV}, 0.277 \mathrm{keV}$ and $0.525 \mathrm{keV}$ correspond to the binding energies of $\mathrm{Cu} \mathrm{L}, \mathrm{S} \mathrm{K}, \mathrm{C} \mathrm{K}$, and $\mathrm{O} \mathrm{K}$, respectively. The carbon and the copper peaks correspond to the SEM holding grid. Throughout the scanning range of binding energies, no obvious peak belonging to impurity is

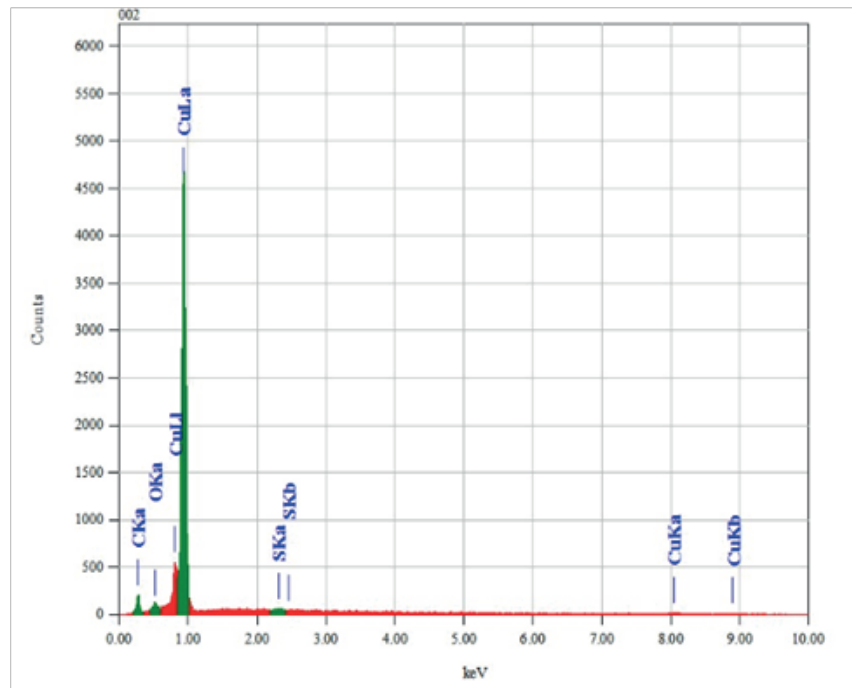

Fig. 5. Energy dispersive $\mathrm{X}$-ray analysis of $\mathrm{Cu}$ nanoparticles

\section{FTIR spectroscopy}

Fig. 6 depicts the FT-IR spectra of modifier 1-dodecanethiol, $\mathrm{C}_{12} \mathrm{~S}-\mathrm{Cu}$ nanoparticles, base oil and produced nanolubricants by dispersing copper nanoparticle in the base oil 


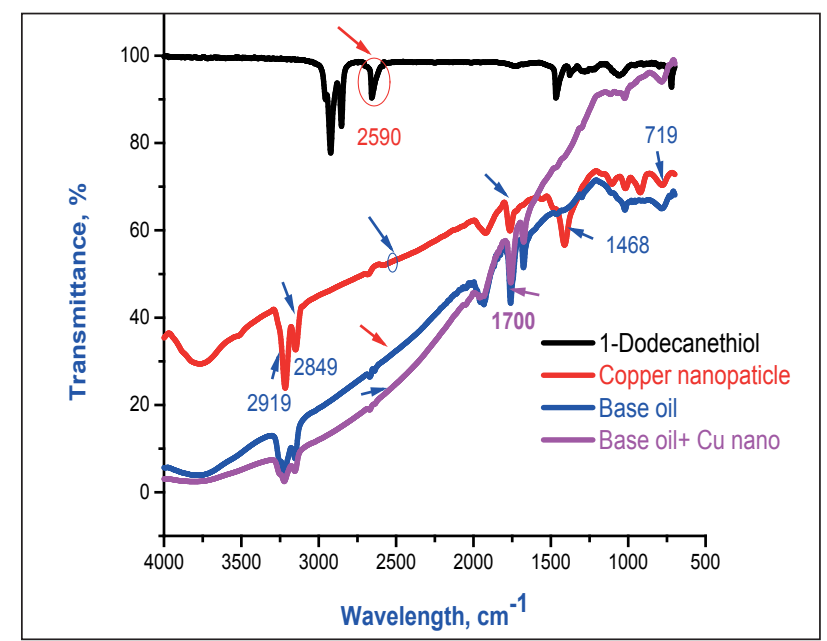

Fig. 6. Overlay FT-IR spectra of the modifier 1-dodecanethiol, synthesized copper nanoparticle, base oil and produced nanolubricants by dispersing copper nanoparticle in the base oil

The absorption band at $2849-2919 \mathrm{~cm}^{-1}$ is attributed to the $\mathrm{C}-\mathrm{H}$ stretch vibration of $-\mathrm{CH}_{3}$ and $-\mathrm{CH}_{2}-$, and the strong absorption at $1468 \mathrm{~cm}^{-1}$ corresponds to the bending vibration of $\mathrm{C}-\mathrm{H} \quad\left(-\mathrm{CH}_{3}\right.$ and $\left.-\mathrm{CH}_{2}^{-}\right)$. Besides, the absorption at $719 \mathrm{~cm}^{-1}$ is assigned to long alkyl chain and the absorption band of $\mathrm{C}_{12} \mathrm{~S}-\mathrm{Cu}$ nanoparticles and dodecanethiol at $880-960 \mathrm{~cm}^{-1}$ is assigned to stretching vibration of $\mathrm{C}-\mathrm{S}$. Moreover, $\mathrm{C}_{12} \mathrm{~S}-\mathrm{Cu}$ nanoparticles or other spectra except the 1-dodecanethiol do not show the $\mathrm{S}-\mathrm{H}$ stretching vibration at $2590 \mathrm{~cm}^{-1}$, which implies that $\mathrm{S}-\mathrm{H}$ is destroyed and $\mathrm{S}$ atom is anchored on the surface of $\mathrm{Cu}$ nanoparticles via strong interaction. The absorption at $1700 \mathrm{~cm}^{-1}$ corresponds to the bending vibration of aromatic $\mathrm{C}=\mathrm{C}$ groups.

\section{$U V$-vis spectroscopy}

$\mathrm{UV}$-vis absorption spectrum of as-synthesized $\mathrm{Cu}$ nanoparticles modified by 1 -dodecanethiol is shown in the Fig.7. The absorption maximum for $\mathrm{C}_{12} \mathrm{~S}-\mathrm{Cu}$ nanoparticle emerges at about $490 \mathrm{~nm}$.

No characteristic absorption band for copper oxide is observed around $800 \mathrm{~nm}$, which provides an evidence for generation of metallic $\mathrm{Cu}$ nanoparticles. The nanoparticles suspension is stable for long time when there are negative surface charges and prevents two particles from aggregating due to strong columbic repulsion leading to a metastable solution of single particles.

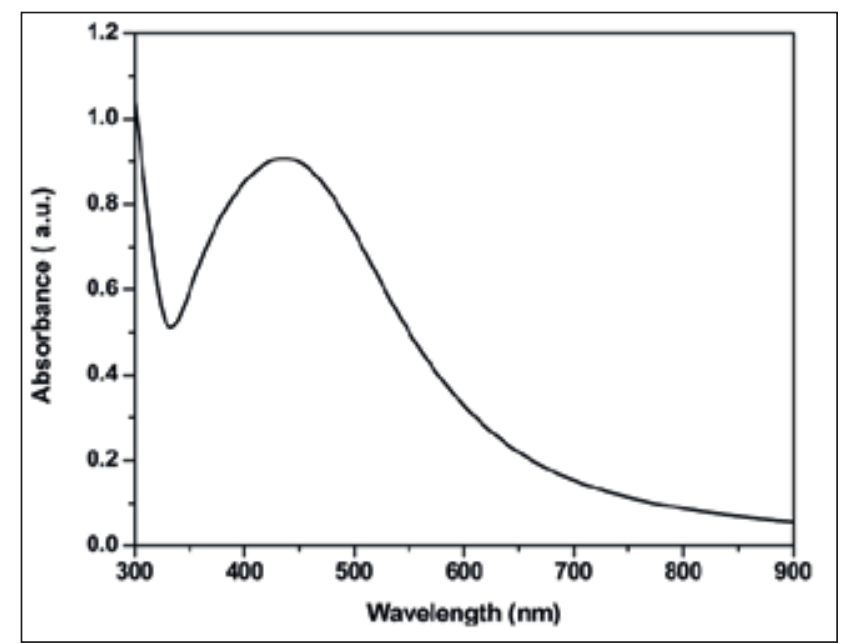

Fig. 7. UV-vis absorption spectra of $\mathrm{Cu}$ nanoparticles surfacecapped by alkanethiol

\section{Effect of Cu-nanoparticle loading on viscosity}

Viscosity of the base oils, lubricating oils containing capped and uncapped copper nanoparticles at two different concentrations $(0.2$ and $0.5 \mathrm{wt} \%)$ and temperatures $\left(40^{\circ} \mathrm{C}\right.$ and $100^{\circ} \mathrm{C}$ ) were measured. The results are shown in the Table I.

Table I Experimental data of viscosity using capped and uncapped copper nanoadditive

The viscosity of nanolubricants at each temperatures increased with increasing concentration of nanoparticles, although the changes in viscosity at lower concentrations is much smaller than that at higher concentrations. The highest amount of increase in viscosity with respect to the base fluid is $18.07 \%$, which is related to the nanolubricants with 0.5 wt $\%$ concentration and at $40^{\circ} \mathrm{C}$ temperature by the sample which was prepared by dispersing $\mathrm{Cu}$ nanoparticles in base oil for $40^{\circ} \mathrm{C}-30 \mathrm{~min}$.

Kinematic viscosities of samples with 0.2 and $0.5 \mathrm{wt} \%$ concentrations $\left(100^{\circ} \mathrm{C}-60 \mathrm{~min}\right)$ decrease compared to the base oils because of the very fine dispersion of $\mathrm{Cu}$ nanoadditive in the base oil at increased temperature and 60 min of dispersion. The interesting point related to the viscosity of nanolubricants with $0.2 \mathrm{wt} \%$ concentration for the kinematic viscosity at $100^{\circ} \mathrm{C}$, is that in each of the two mentioned temperatures $\left(40^{\circ} \mathrm{C}\right.$ and $\left.100^{\circ} \mathrm{C}\right)$ of the produced samples, the viscosity of the oil which did not contain $\mathrm{Cu}$ nanoparticles had a very slight decrease. When nanoparticles 
Table I. Experimental data of viscosity using capped and uncapped copper nanoadditive

\begin{tabular}{ccccc}
\hline & \multicolumn{2}{c}{ Surface capped Cu-nanoadditive } & \multicolumn{2}{c}{ Uncapped Cu-nanoadditive } \\
& $\begin{array}{c}\text { Viscosity at } \\
40^{\circ} \mathrm{C}(\mathrm{cSt})\end{array}$ & $\begin{array}{l}\text { Viscosity at } \\
100^{\circ} \mathrm{C}(\mathrm{cSt})\end{array}$ & $\begin{array}{c}\text { Viscosity at } \\
40^{\circ} \mathrm{C}(\mathrm{cSt})\end{array}$ & $\begin{array}{c}\text { Viscosity at } 100^{\circ} \mathrm{C} \\
(\mathrm{cSt})\end{array}$ \\
\hline Base oil & 284.875 & 38.471 & 284.875 & 38.471 \\
$0.2 \mathrm{wt} \%$ & 338.625 & 31.9083 & 305.71 & 27.35 \\
$\left(40^{\circ} \mathrm{C}-30 \mathrm{~min}\right)$ & & & & 32.73 \\
$0.5 \mathrm{wt} \%$ & 341.744 & 37.1132 & 312.744 & 28.05 \\
$\left(40^{\circ} \mathrm{C}-30 \mathrm{~min}\right)$ & & & 220.5 & \\
$0.2 \mathrm{wt} \%$ & 227.9 & 33.945 & & 38.98 \\
$\left(100^{\circ} \mathrm{C}-60 \mathrm{~min}\right)$ & & & 217.6 & \\
$0.5 \mathrm{wt} \%$ & 223.6 & 40.734 & & \\
$\left(100^{\circ} \mathrm{C}-60 \mathrm{~min}\right)$ & & & & \\
\hline
\end{tabular}

are added to the oil, they are placed between the oil layers and lead to ease of fluid layer movement on each other. As a result, viscosity slightly decreases. As concentration increases, nanoparticles agglomerate and create larger and asymmetric particles, which prevent movement of oil layers on each other, so viscosity increases. Therefore, the sample at $0.5 \mathrm{wt} \%$ concentration exhibited increase in the viscosity than the base fluid.

It can be concluded that the viscosity of SN 150 base oil which contains $\mathrm{Cu}$ nanoparticles is a function of concentration of nanoparticles and at lower concentrations it has minor change with respect to the viscosity of the base oil. Similar results were obtained when uncapped copper nanoparticles were dispersed in the base oil. But the only difference is that, the improvement of the viscosity of base fluid was very little compared to surface-capped copper nanoadditive due to the absence of desired protecting layer as there was no capping agent used in the synthesis process. As a result, particle agglomeration occurred. It is obvious that the rate of improvement of the viscosity change is very much similar to the results obtained by using surface-capped copper nanoparticles but the average percentage of improvement is poor compared to the surface-capped copper nanoparticles due to the agglomeration of the uncapped copper nanoparticles.
Effect of Cu-nanoparticle loading on flash point and pour point

Table II shows that addition of $\mathrm{Cu}$ nanoparticles to the base oil causes an increase in flash point and pour point of the base oil. Increase in thermal conductivity through addition of nanoparticles is attributed to the increase of oil resistance against ignition. Also, flash point has a direct relation with concentration of nanoparticles, although this relation is not linear and the intensity changes in lower concentrations are more than the changes at higher concentrations. The increase in flash point of the nanofluid at $0.2 \mathrm{wt} \%$ concentration with respect to the base fluid is $11 \%$, and the highest amount of increase is related to the $0.5 \mathrm{wt} \%$ sample, which is $26 \%$.It can also be observed that in $0.5 \mathrm{wt} \%$ concentrations (both the samples made in $40^{\circ} \mathrm{C}$ and $100^{\circ} \mathrm{C}$ ) the pour point decreased due to the presence of excess nanoadditive which create particle agglomeration, but in the $0.2 \mathrm{wt} \%$ concentration, there was $9.7 \%$ improvement with respect to the base oil.

\section{Conclusion}

Copper nanoparticles could be prepared in a two-phase system in the presence of stabilizer CTAB and reductant hydrazine hydrate. Particle size and its distribution can be controlled by adjusting the synthesis parameters such as concentration of $\mathrm{CuSO}_{4}, \mathrm{pH}$ and ratio of $\mathrm{CTAB}$ to $\mathrm{CuSO}_{4}$. 
Table II. Experimental data of flash point and pour point

\begin{tabular}{cccccc}
\hline & & \multicolumn{4}{c}{ Nanolubricants } \\
\cline { 3 - 5 } & Base oil & $0.2 \mathrm{wt} \%$ & $0.5 \mathrm{wt} \%$ & $0.2 \mathrm{wt} \%$ & $0.5 \mathrm{wt} \%$ \\
& & $\left(40{ }^{\circ} \mathrm{C}-30 \mathrm{~min}\right)$ & $\left(40{ }^{\circ} \mathrm{C}-30 \mathrm{~min}\right)$ & $\left(100{ }^{\circ} \mathrm{C}-60 \mathrm{~min}\right)$ & $\left(100{ }^{\circ} \mathrm{C}-60 \mathrm{~min}\right)$ \\
\hline Flash point & $49{ }^{\circ} \mathrm{C}$ & $53{ }^{\circ} \mathrm{C}$ & $54{ }^{\circ} \mathrm{C}$ & $72{ }^{\circ} \mathrm{C}$ & $80{ }^{\circ} \mathrm{C}$ \\
Pour point & $-13{ }^{\circ} \mathrm{C}$ & $-17.5{ }^{\circ} \mathrm{C}$ & $-11.5{ }^{\circ} \mathrm{C}$ & $-18{ }^{\circ} \mathrm{C}$ & $-12{ }^{\circ} \mathrm{C}$ \\
\hline
\end{tabular}

CTAB plays an important role in terms of dispersibility of copper nanoparticles, and it inhibits the agglomeration of $\mathrm{Cu}$ particles before being surface-capped by modifier dodecanethiol. Alkanethiol-capped $\mathrm{Cu}$ nanoparticles can be harvested through ligand exchange, since $\mathrm{CTAB}$ as a ligand is weaker than thiols. Ultrasonic method for dispersing copper nanoparticles inside the base fluid is the most suitable method because it supplies high energy preventing their agglomeration and precipitation. Nanolubricants with 0.2 $\mathrm{wt} \%$ concentration have been found to be the best samples for $\mathrm{Cu} /$ oil with improved pour point and flash point and insignificant change in viscosity. It can be concluded that the methods of preparation and dispersion can produce about 40-60 nm of spherical copper nanoadditive with good dispersion property in the base oil.

\section{Acknowledgement}

The authors acknowledge the technical support provided by the Department of Applied Chemistry and Chemical Engineering, University of Dhaka, Dhaka-100, Bangladesh.

\section{References}

Ang TP, Wee TSA and Chin WS (2004), Three-dimensional self-assembled monolayer (3D SAM) of $n$-alkanethiols on copper nanoclusters, J. Phys. Chem. B 108: 1100111010. DOI: $10.1021 /$ jp049006r

Choi Y, Lee C, Hwang Y, Park M, Lee J, Choi C and Jung M (2009), Tribological behavior of copper nanoparticles as additives in oil, Curr. Appl. Phys. 9: e124-e127.

Chen L, Zhang D, Chen J, Zhou H and Wan H (2006), The use of CTAB to control the size of copper nanoparticles and the concentration of alkylthiols on their surfaces, Mater. Sci. Eng. A 415: 156-161.

Chinas-Castillo F and Spikes HA (2004), The behavior of diluted sooted oils in lubricated contacts, Tribol. Lett. 16: 317-322. DOI: org/10.1023/B:TRIL.0000
Cushing BL, Kolesnichenko VL and O'Connor CJ (2004), Recent advances in the liquid-phase syntheses of inorganic nanoparticles, Chem. Rev.104: 3893-3946.

Chinas-Castillo F and Spikes HA (2003), Mechanism of action of colloidal solid dispersions, J. Tribol. 125: 552-557. DOI: 10.1115/1.1537752

Dung DTM, Tuyet LTT, Fribourg-Blanc E and Chien DM (2011), The influence of solvents and surfactants on the preparation of copper nanoparticles by a chemical reduction method, Adv. Nat. Sci: Nanosci. Nanotechnol. 2: 025004-025011.

Dhas NA, Raj CP and Gedanken A (1998), Synthesis, characterization, and properties of metallic copper nanoparticles, Chem. Mater. 10: 1446-1452.

Grouchko M, Kamyshny A, Ben-Ami K and Magdassi S (2009), Synthesis of copper nanoparticles catalyzed by pre-formed silver nanoparticles, J. Nanopart. Res. 11: 713-716.

Garg J, Poudel B, Chiesa M, Gordon JB, Ma JJ, Wang J B, Ren Z F, Kang Y T, Ohtani H, Nanda J, McKinley GH and Chen G (2008), Enhanced thermal conductivity and viscosity of copper nanoparticles in ethylene glycol nanofluid, J. Appl. Phys. 103: 1-6. DOI: org $/ 10.1063 / 1.2902483$

Hou Y, Kondoh H, Ohta T and Gao S (2005), Size-controlled synthesis of nickel nanoparticles, Appl. Surf. Sci. 241: 218-222. DOI: org/10.1016/j.apsusc.2004.09.045

Henglein A (1998), Small-particle research: physicochemical properties of extremely small colloidal metal and semiconductor particles, Chem. Rev. 89: 1861-1873.

Huang HH, Yan FQ, Kek YM, Chew CH, Xu GQ, Ji W, Oh PS and Tang SH (1997), Synthesis, characterization, and nonlinear optical properties of copper nanoparticles, Langmuir 13: 172-175. 
Judai K, Numao S, Nishijo J and Nishi N (2011), In situ preparation and catalytic activation of copper nanoparticles from acetylide molecules, J. Mol. Catal. A: Chem. 347: 28-33. DOI: org/10.1016/ j.molcata. 2011.07.006

Joshi SS, Patil S F, Iyer V and Mahumuni S (1998), Radiation induced synthesis and characterization of copper nanoparticles. Nanostruct. Mater. 10: 1135-1144.

Kumari P and Majewski P (2013), Adsorption of albumin on silica surfaces modified by silver and copper nanoparticles, J. Nanomater. 2013: 1-7.

Kumar SA, Cheng H-W, Chen S-M and Wang S-F (2010), Preparation and characterization of copper nanoparticles/zinc oxide composite modified electrode and its application to glucose sensing, Mater. Sci. Eng. C 30: 86-91. DOI: org/10.1016/j.msec.2009.09.001

Khanna PK, Gaikwad S, Adhyapak PV, Singh N and Marimuthu R (2007), Synthesis and characterization of copper nanoparticles, Mater. Lett. 61: 4711-4714.

Kumar RV, Mastai Y, Diamant Y and Gedanken A (2001), Sonochemical synthesis of amorphous $\mathrm{Cu}$ and nanocrystalline $\mathrm{Cu}_{2} \mathrm{O}$ embedded in a polyaniline matrix, J. Mater. Chem. 11: 1209-1213.

Luo N, Liu KX, Li XJ, Wu ZW, Wu SY, Yea LM and Shena Y (2012), Synthesis of graphite-coated copper nanoparticles by the detonation of a copper-doped emulsion explosive, Mendeleev Commun. 22: 248-249.

Lee K, Hwang Y, Cheong S, Choi Y, Kwon L, Lee J and Kim SH (2009), Understanding the role of nanoparticles in nanooil lubrication, Tribol. Lett. 35: 127-131.

Li Y, Afzaal M and O'Brien P (2006), The synthesis of amine-capped magnetic (Fe, Mn, Co, Ni) oxide nanocrystals and their surface modification for aqueous dispersibility, J. Mater. Chem. 16: 21752180. DOI: 10.1039/B517351E

Liu WM and Chen S (2000), An investigation of the tribological behaviour of surface-modified $\mathrm{ZnS}$ nanoparticles in liquid paraffin, Wear 238: 120-124.

Lisiecki I, Sack-Kongehl H, Weiss K, Urban J and Pileni M P (2000), Annealing process of anisotropic copper nanocrystals.2.Rods, Langmuir 16: 8807-8808.
Lisiecki I, Billoudet F and Pileni MP (1996), Control of the shape and the size of copper metallic particles, J. Phys. Chem.100: 4160-4166. DOI: 10.1021/jp9523837

Lisiecki I and Pileni MP (1993), Synthesis of copper metallic clusters using reverse micelles as microreactors, J. Am. Chem. Soc. 115: 3887-3896.

Langford JI and Wilson AJ (1978), Scherrer after sixty years: a survey and some new results in the determination of crystallite size, J. Appl. Crystallogr. 11: 102-113.

Monshi A, Foroughi MR and Monshi MR (2012), Modified Scherrer equation to estimate more accurately nanocrystallite size using XRD, World J. Nano Sci. Eng. 2: 154-160. DOI:10.4236/wjnse.2012.23020

Mamun M A-Al, Kusumoto Y and Muruganandham M (2009), Simple new synthesis of copper nanoparticles in water/acetonitrile mixed solvent and their characterization, Mater. Lett. 63: 2007-2009.

Musa AO, Akomolafe T and Carter MJ (1998), Production of cuprous oxide, a solar cell material, by thermal oxidation and a study of its physical and electrical properties, Solar Energy Materials and Solar Cells 51: 305-316. DOI: org/10.1016/S0927-0248(97)00233-X

Pacioni NL, Pardoe A, McGilvray KL, Chr'etien MN and Scaiano JC (2010), Synthesis of copper nanoparticles mediated by photogenerated free radicals: catalytic role of chloride anions, Photochem. Photobiol. Sci. 9: 766-774. DOI: 10.1039/B9PP00200F

Park BK, Kim D, Jeong S, Moon J and Kim J S (2007), Direct writing of copper conductive patterns by ink-jet printing, Thin Solid Films 515: 7706-7711.

Park BK, Jeong S, Kim D, Moon J, Lim S and Kim JS (2007a), Synthesis and size control of monodisperse copper nanoparticles by polyol method, J. Colloid Interface Sci. 311: 417-424.

Puntes VF, Krishnan KM and Alivisatos AP (2001), Colloidal nanocrystal shape and size control: the case of cobalt, Science 291: 2115-2117.

Pileni MP, Ninham BW, Gulik-Krzywicki T, Tanori J, Lisiecki I and Filankembo A (1999), Direct relationship between shape and size of template and synthesis of copper metal particles, Adv. Mater. 11: 1358-1362. 
Qi L, Ma J and Shen J (1997), Synthesis of copper nanoparticles in nonionic water-in-oil microemulsions, J. Colloid Interface Sci. 186: 498-500.

Radtchenko IL, Sukhorukov GB, Gaponik N, Kornowski A, Rogach AL and Mohwald H (2001), Core-shell structures formed by the solvent-controlled precipitation of luminescent CdTe nanocrystals on latex spheres, Adv. Mater. 13: 1684-1687.

Shi PJ, Yu HL, Wang HM and Xu BS (2013), Tribological behaviour of surface modified copper nanoparticles as lubricating additives, Phys. Procedia 50: 461-465. DOI: org/10.1016/j.phpro.2013.11.072

Seo JY, Kang HW, Jung DS, Lee HM and Park SB (2013), One step synthesis of copper nanoparticles embedded in carbon composites, Mater. Res. Bull. 48: 1484-1489. DOI: org/10.1016/j.materresbull. 2012.12.070

Shen SL, Zhuang J, Xu XX, Nisar A, Hu S and Wang X (2009), Size effects in the oriented-attachment growth process: the case of $\mathrm{Cu}$ nanoseeds, Inorg. Chem. 48: 5117-5128.

Sun L, Zhou J F, Zhang Z J and Dang HX (2004), Synthesis and tribological behavior of surface modified $\left(\mathrm{NH}_{4}\right)_{3} \mathrm{PMo}_{12} \mathrm{O}_{40}$ nanoparticles, Wear 256: 176-181.

Sun YG and Xia YN (2002), Shape-controlled synthesis of gold and silver nanoparticles, Science 298: 2176-2179. DOI: 10.1126/science. 1077229

Xu T, Zhao JZ and Xu K (1996), The ball-bearing effect of diamond nanoparticles as an oil additive, J. Phys. D 29: 2932-2937.

Yeh MS, Yang YS, Lee YP, Lee HF, Yeh YH and Yeh CS (1999), Formation and characteristics of $\mathrm{Cu}$ colloids from $\mathrm{CuO}$ powder by laser irradiation in 2-propanol, J. Phys. Chem. 103: 6851-6857.
Zhang BS, Xu BS, Xu Y, Gao F, Shi PJ and Wu YX (2011), $\mathrm{Cu}$ nanoparticles effect on the tribological properties of hydrosilicate powders as lubricant additive for steel-steel contacts, Tribol. Int. 44: 878-886. DOI: org/10.1016/j.triboint.2011.03.002

Zhang YD, Yan JS, Yu LG and Zhang PY (2010), Effect of nano- $\mathrm{Cu}$ lubrication additive on the contact fatigue behavior of steel, Tribol. Lett. 37: 203-207.

Zhang M, Wang X, Liu W and Fu X (2009), Performance and anti-wear mechanism of $\mathrm{Cu}$ nanoparticles as lubricating oil additives, Ind. Lubr.Tribol. 61: 311-318. DOI: org/10.1108/00368790910988426

Zhu F, Fan W, Wang A and Zhu Y (2009), Tribological study of novel S-N style 1,3,4-thiadiazole-2thione derivatives in rapeseed oil, Wear 266: 233-238. DOI: org/10.1016/j.wear.2008.06.016

Zhang H, Cui Z, Wang Y, Zhang K, Ji X, Lu C, Yang B and Gao M (2003), From water-soluble CdTe nanocrystals to fluorescent nanocrystal-polymer transparent composites using polymerizable surfactants, Adv. Mater. 15: 777-780.

Ziegler KJ, Doty RC, Johnston KP and Korgel BA (2001), Synthesis of organic monolayer-stabilized copper nanocrystals in supercritical water, J. Am. Chem. Soc. 123: 7797-7803.

Zhou JF, Wu ZS, Zhang ZJ, Liu WM and Dang HX (2001), Study on an antiwear and extreme pressure additive of surface coated $\mathrm{LaF}_{3}$ nanoparticles in liquid paraffin, Wear 249: 333-337. DOI: org/10.1016 /S0043-1648(00)00547-0 